\title{
A rare case of Pacinian corpuscle neuroma
}

\author{
VB Narayanamurthy FRCS(G), A Thomas Winston MBBS DipNBSurgery MRCS, Amit Gupta MBBS DipNBSurgery MRCS
}

VB Narayanamurthy, AT Winston, A Gupta. A rare case of Pacinian corpuscle neuroma. Can J Plast Surg 2005;13(1):43-45.

The authors discuss an interesting case of a Pacinian corpuscle neuroma in the thumb of an elderly woman who presented with severe digital pain. The pain was initially attributed to osteoarthritis of the interphalangeal joint of the thumb. The clinical signs were very subtle. The patient had complete pain relief following excision of the tumour. Pacinian corpuscle neuromas are rare, with only about 70 cases reported in the literature. The histology, presenting features and associated conditions are discussed in detail. In addition to a neuroma or glomus tumour, Pacinian corpuscle hyperplasia should be considered in the differential diagnosis of digital or palmar pain of unknown etiology.

Key words: Pacinian cell neuroma; Pacinian corpuscle neuroma; Painful hand lesions

$\mathrm{P}$ acinian corpuscles are mechanoreceptors found in man and other animals. They are distributed in the dermis from the fingers and palm of the hand, the conjunctiva, near joints, in the mesenteries, branching blood vessels, penis, urethra, clitoris, parietal peritoneum and loose connective tissue.

The Pacinian corpuscle is a pressure receptor that responds to high-frequency vibratory stimuli. The corpuscle is fluidfilled and essentially incompressible. It consists of a single nerve fibre, the terminal region of which is enclosed in a multilaminated connective tissue capsule. The nerve is myelinated except for the terminal region within the capsule, which is nonmyelinated. The corpuscle transmits mechanical stimuli through the connective tissue lamellae and fluid, exciting the nonmyelinated receptor axon in its core (Figures 1, 2 and 3).

These end-organs are the only sensory receptors that are large enough to be identified and dissected in the anatomy laboratory. They should be looked for when dissecting the palm of the hand and fingers.

There are approximately 300 Pacinian corpuscles in the hand. They are distributed in fingers $(60 \%)$, near the metacarpophalangeal joints $(25 \%$ to $48 \%)$ and in the thenar and hypothenar regions ( $8 \%$ to $18 \%$ ) (1). A neuroma may sometimes arise from this Pacinian corpuscle. We present an interesting case of a woman with Pacinian corpuscle neuroma of the thumb.

\section{Cas rare de névrome des corpuscules de Pacini}

Voici un cas intéressant de névrome des corpuscules de Pacini dans le pouce, observé chez une femme âgée qui a consulté pour des douleurs importantes au doigt. La douleur a d'abord été attribuée à une atteinte arthrosique de l'articulation interphalangienne du pouce; les signes cliniques étaient très discrets. Finalement, l'excision de la tumeur a permis un soulagement complet de la douleur. Les névromes des corpuscules de Pacini sont rares; la documentation médicale ne fait état que de 70 cas à peu près. Nous traiterons en détail, dans le présent article, d'histologie, de signes d'appel et d'affections associées. Outre les névromes ou les tumeurs du glomus de Masson, l'hyperplasie des corpuscules de Pacini devrait être envisagée dans le diagnostic différentiel des douleurs digitales ou palmaires d'origine inconnue. 


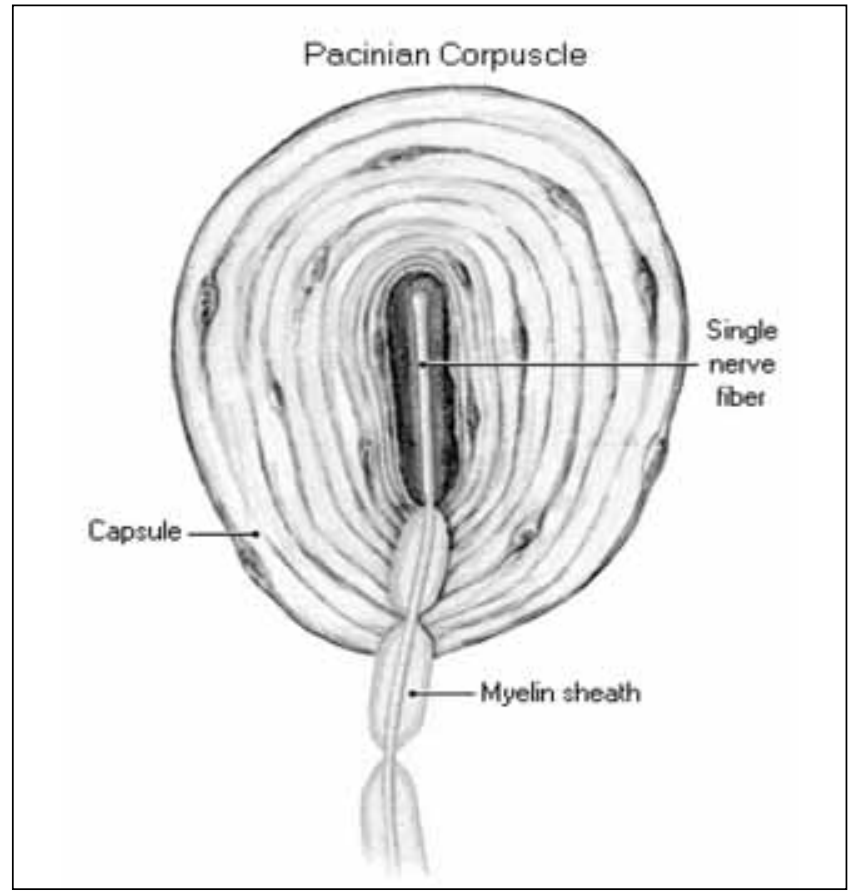

Figure 1) Schematic diagram of the microscopic structure of a Pacinian corpuscle showing a single unmyelinated nerve fibre surrounded by connective tissue lamellae. The part of the nerve outside the capsule is myelinated

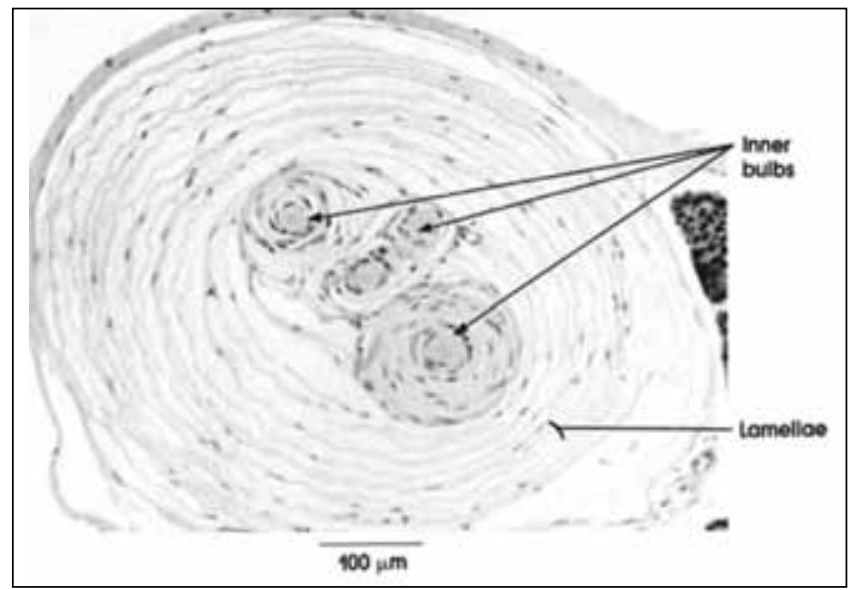

Figure 2) Microscopic structure of a normal Pacinian corpuscle showing the inner bulb (transverse section of branches of terminal unmyelinated nerve endings) and lamellae (concentric layers of collagenous connective tissue and flattened fibroblasts)

patient had complete pain relief. Gross pathology showed grape-like clusters of Pacinian corpuscles. Microscopic examination revealed mature Pacinian corpuscles that were increased in size and number associated with degenerative changes and fibrosis of the adjacent tissues (Figures 3, 4 and 5).

\section{DIFFERENTIAL DIAGNOSIS}

The lesions that present with pain in the hand include osteoarthritis, osteoid osteoma, synovioma, schwannoma and traumatic aneurysm. Among these lesions, glomus tumour and schwannoma elicit point tenderness.

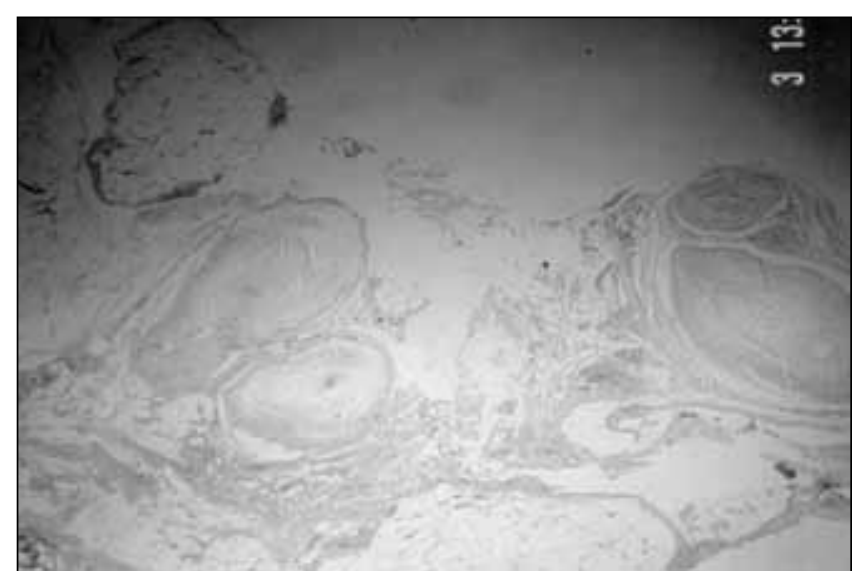

Figure 3) Low-power view of Pacinian corpuscle neuroma showing increase in size and number of Pacinian corpuscles

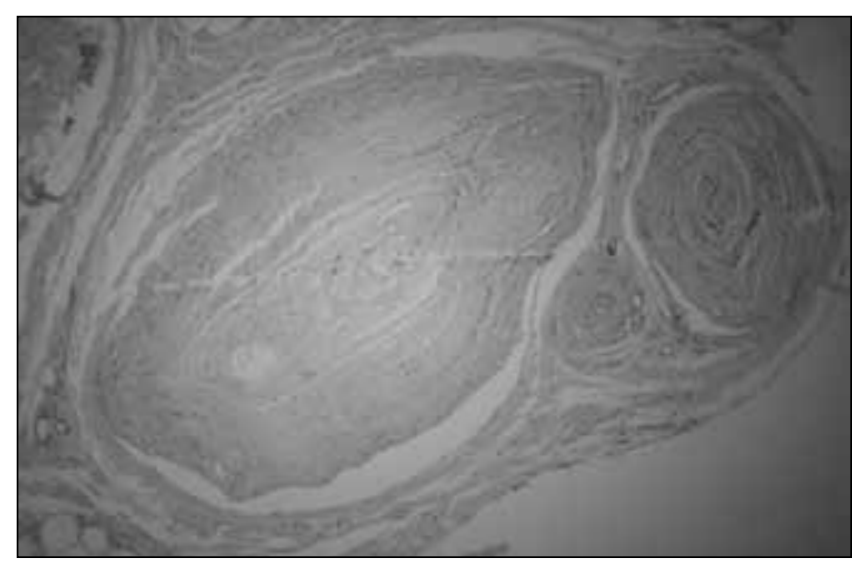

Figure 4) Low-power view of Pacinian corpuscle neuroma showing Pacinian corpuscles with flattened surrounding tissues

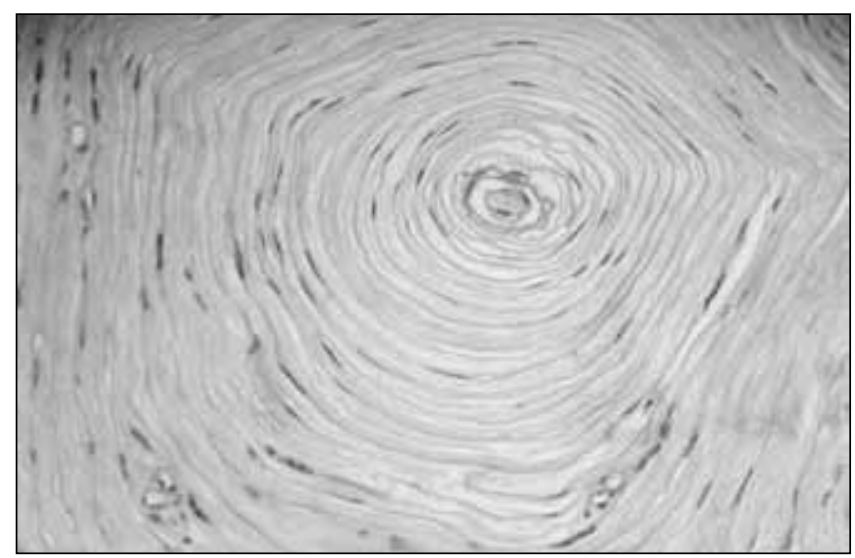

Figure 5) High-power view of Pacinian corpuscle neuroma showing inner nerve fibre surrounded by concentric fibrous lamellae

\section{REVIEW OF LITERATURE}

Pacinian corpuscle neuroma is an uncommon lesion with a limited number of cases reported. This lesion can be called variably as Pacinian corpuscle hyperplasia or Pacinian corpuscle neuroma (2-7).

The most common site of this lesion is the hand, where it presents as painful swelling. A prior history of trauma may be elicited in a majority of the patients and it may be associated 
with foreign body reaction (8). All of the patients experienced complete pain relief following excision of the tumour.

Similar lesions have been described in other parts of the body as well. They include Pacinian neuroma of vulva, Pacinian hyperplasia of foot, sacrococcygeal pacinioma and intraperitoneal pacinian neuroma (9-13).

Pacinian corpuscle neuromas may be associated with other lesions such as glomus tumour, Dupuytren's contracture, multiple Pacinian neuroma and arteriovenous anastomoses (14-16).

\section{CONCLUSIONS}

Pacinian corpuscle neuroma is a rare lesion with a limited number of cases reported in the literature. The terminology used may be confusing because Pacinian cell hyperplasia and neuroma are used interchangeably. All of the reported cases were benign. There is complete pain relief following excision of the tumour. Eliciting point tenderness and an early exploration in suspicious hand swelling with sparse clinical signs help in the diagnosis and treatment of this extremely uncommon condition.

\section{REFERENCES}

1. Stark B, Carlstedt T, Hallin RG, Risling M. Distribution of human Pacinian corpuscles in the hand. A cadaver study. J Hand Surg $[\mathrm{Br}]$ 1998;23:370-2.

2. Kumar A, Darby AJ, Kelly CP. Pacinian corpuscles hyperplasia an uncommon cause of digital pain. Acta Orthop Belg 2003;69:74-6.
3. Fletcher CD, Theaker JM. Digital pacinian neuroma: A distinctive hyperplastic lesion. Histopathology 1989;15:249-56.

4. Fraitag S, Gherardi R, Wechsler J. Hyperplastic pacinian corpuscles: An uncommonly encountered lesion of the hand. J Cutan Pathol 1994:21:457-60.

5. Patterson TJ. Pacinian corpuscle neuroma of the thumb pulp. Br J Plast Surg 1956;9:230-1.

6. Rhode CM, Jennings WD Jr. Pacinian corpuscle neuroma of digital nerves. South Med J 1975;68:86-9.

7. Jones NF, Eadie P. Pacinian corpuscle hyperplasia in the hand. J Hand Surg [Am] 1991;16:865-9.

8. Rinaldi P, Andreini A, Ercolani C, Bernardi L, Bernardi S. [Digital pacinian hyperplasia. Report of a case associated with foreign body reaction]. Pathologica 2000;92:36-40.

9. Satge D, Nabhan J, Nandiegou Y, Hermann B, Goburdhun J, Labrousse F. A Pacinian hyperplasia of the foot. Foot Ankle Int 200;22:342-4.

10. Dembinski AS, Jones JW. Intra-abdominal pacinian neuroma: A rare lesion in an unusual location. Histopathology 1991;19:89-90.

11. Guidugli Neto J. [Intraperitoneal pacinian neurofibroma (enlarged pacinian corpuscles)]. Rev Paul Med 1990;108:192.

12. Medina Perez M, Rafel Ribas E, Valero Puerta JA, Perez Martin D. [Pacinian neurofibroma of the vulva]. Arch Esp Urol 2000;53:634-6.

13. Bale PM. Sacrococcygeal paciniomas. Pathology 1980;12:231-5.

14. Akyurek N, Ataoglu O, Cenetoglu S, Ozmen S, Cavusoglu T, Yavuzer R. Pacinian corpuscle hyperplasia coexisting with Dupuytren's contracture. Ann Plast Surg 2000;45:220-2.

15. Levi L, Curri SB. Multiple Pacinian neurofibroma and relationship with the finger-tip arterio-venous anastomoses. Br J Dermatol 1980;102:345-9.

16. Greider JL Jr, Flatt AE. Glomus tumor associated with pacinian hyperplasia - case report. J Hand Surg [Am] 1982;7:113-7. 